\title{
Six Sigma Case : The Improvement Welding Strength of LED Soft Board Process
}

\author{
Chien-Chih Wang*, Chun-Hua Chien, Chi-Wei Chang \\ Department of Industrial Engineering and Management, Ming Chi University of Technology, New Taipei, Taiwan \\ *Corresponding Author: ieccwang@mail.mcut.edu.tw
}

\begin{abstract}
The flexible circuit board has a flexible folding characteristic. When the welding strength decreases with the volume of the electronic parts, the reliability will be lower than that of the general rigid circuit board. Therefore, it is an urgent issue to improve the quality of soft circuit board to improve the strength of component surface adhesion. Based on a six-sigma framework, this study optimizes quality through process data analysis. The results show that the optimal combination of conditions can increase the thrust value from $0.8 \mathrm{~kg}$ to $1.3 \mathrm{~kg}$ and achieve the desired quality goal. The specific benefit is to reduce the company's quality failure cost of NT $\$ 8.9$ million per year.
\end{abstract}

Keywords: Flexible circuit board, DMAIC, Reliability, Design of experiment, Quality cost

\section{Introduction}

The surface sticking component is small in size and meets the demand for electronic products. It is the primary method to stick the electronic components on the printed circuit board. The technique is to fix the components on the surface of the printed circuit board after applying the solder paste. At present, the quality problem of our cooperative manufacturers is that the welding strength of components decreases with the reduction of volume. In particular, the flexible circuit board has the characteristics of flexible folding, which leads to the reliability of its weldability is lower than the general hardboard. Therefore, how to find out the best welding process conditions to improve the strength has become an urgent problem for manufacturers. In this study, a six-sigma six analysis framework was applied to solve the current projects entrusted by the cooperative manufacturers. Six-sigma is the method to find the best solution for complex problems by clarifying the problems, collecting data, understanding the causes, and so on.

In the past, there have been many successful cases using Six Sigma methodology-DMAIC (define, measure, analyze, improve, control) to solve current manufacturing quality problems $[1,2,3]$. Huang et al., improve the inventory control system by applying Six Sigma. With the introduction of radio-frequency identification into inventory- checking procedures, results showed that there were $47 \%$ reduction in the procedures, $53 \%$ reduction in the time, $53 \%$ reduction in the number of labors involved in the inventory- checking process [4]. Chan et al., used the six-sigma method to determine the optimal parameters of the vertical continuous plating equipment so that each substrate can be produced by the same process, which not only reduces the difference between the finished products, but also through the new mechanism design to solve copper thickness variations between substrate edges and designated graphic designs [5] .

\section{Methodology}

The case study M company, founded in 1992, is a professional soft circuit board manufacturer with about 5000 employees. The problem point of the case is that $\mathrm{T}$ company, an important customer, caused the LED to fall off due to the narrow mechanism and straightforward collision with the soft board when assembling the soft board online, which caused the external loss of the company up to 296,836 USD.

\subsection{Define phase}

According to the general industry standard, the thrust of LED welding on the soft plate should be more than $1 \mathrm{~kg}$, while the actual measurement of the current product is the only $0.8 \mathrm{~kg}$. Due to the product design, the shell is not easy to assemble due to the limited assembly space of customer $\mathrm{T}$ 
in the production line. As a result, it is easy to touch the LED in the assembly process. Besides, the LED of the soft plate falls off due to insufficient weldability, resulting in reduced functionality. The goal of the definition stage is to raise the LED thrust value from the original $0.8 \mathrm{k}$ to more than $1.2 \mathrm{~kg}$. First, SIPOC is used to confirm the process inputs and outputs that affect the critical factors. According to C\&E analysis, the primary sources of variation summarized as follows: (1) surface treatment-protective film position deviation; (2) gold-plated area; (3) screen printing - screen board (ink leakage and migration); (4) grooving (thickness and deviation) of SMT- steel plate and rewelding temperature curve.

\subsection{Measure phase}

The measure phase is mainly used to measure the thrust value of the parts of the universal pull thrust machine, the implementation of measurement system analysis. The universal puller is operated by applying a horizontal force to push the LED until the LED falls off on the FPC and stops and records the maximum allowable force of the LED (figure 1).
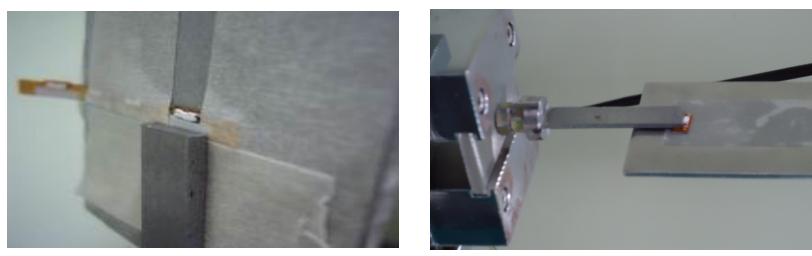

Fig.1. The relationship between universal puller and thrust force.

Practice for the arrangement of personnel to do the measurement of the machine, verify the stability of the machine measurement. Use $0.5 \mathrm{~kg}$ standard weight to measure the weight pulled by the tension machine, three times a day (morning, middle, and evening), need to measure continuously for 20 working days. Results from the control chart (figure 2), the machine has stability. After the measurement stage, confirm the direction that affects the welding strength, which can be classified into two categories, active welding area, and SMT operating conditions.

\subsection{Analysis phase}

Due to the position of the protective film offset, the plating area, mesh plate leakage, and offset will affect the active welding area. Firstly, it is necessary to analyze whether there is a correlation between the exposed area of the LED pad and the thrust value of parts.

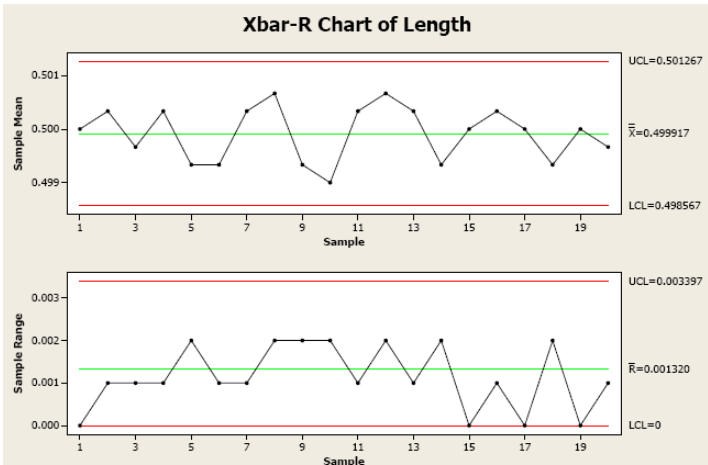

Fig.2. Control chart for stability measurement analysis of machine

In order to verify its correlation, the Coverlay fitting deviation (figure 3) and Coverlay without deviation (figure 4) were compared, respectively.
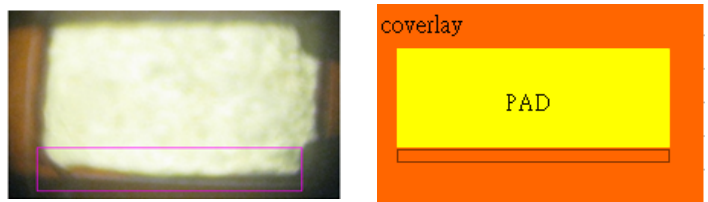

Fig.3. The schematic diagram of the PAD area decreases due to Coverlay fitting deviation.
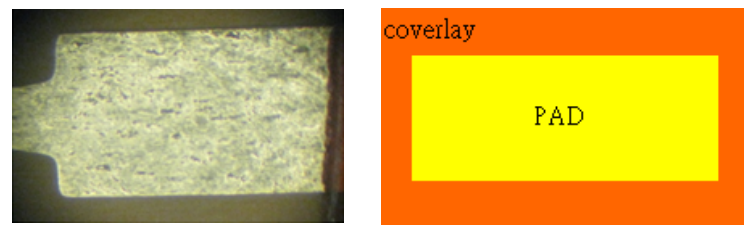

Fig.4. The schematic diagram of wholly exposed PAD due to Coverlay without offset

By taking 20 groups of samples for analysis and comparison, it can be found from figure 5 that the effective welding area of PAD directly affects the welding reliability.

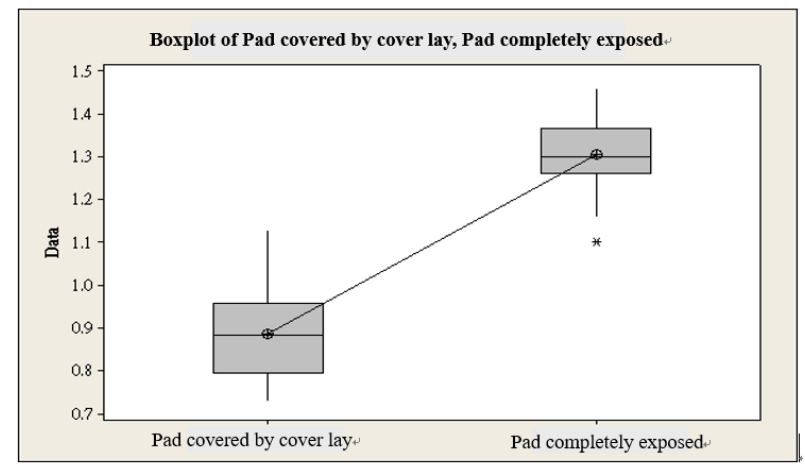

Fig.5. The Boxplot of pad area and thrust value

The steel plate is one of the critical materials in the SMT printing process. According to the position of FPC part PAD, dig out the opening at the corresponding place of the steel plate. The solder paste is printed on the FPC through these openings. Therefore, whether the part is offset depends on whether the steel plate opening is offset, resulting in 
solder paste printing deviation. The thickness of the solder paste depends on the thickness of the steel sheet. To verify the dependence of tin thickness and part offset on thrust values, two sets of experiments were tested separately. The first group is under regular operation, the tin thickness is $100 \mathrm{um}$, and the control group is increased to $120 \mathrm{um}$; the second group is regular operation and steel plate offset. Each group of 25 samples was compared. Figure 6 shows that the thickness of the solder paste directly affects the reliability of the soldering. Figure 7 shows that the effect of the soldering offset is not significant.

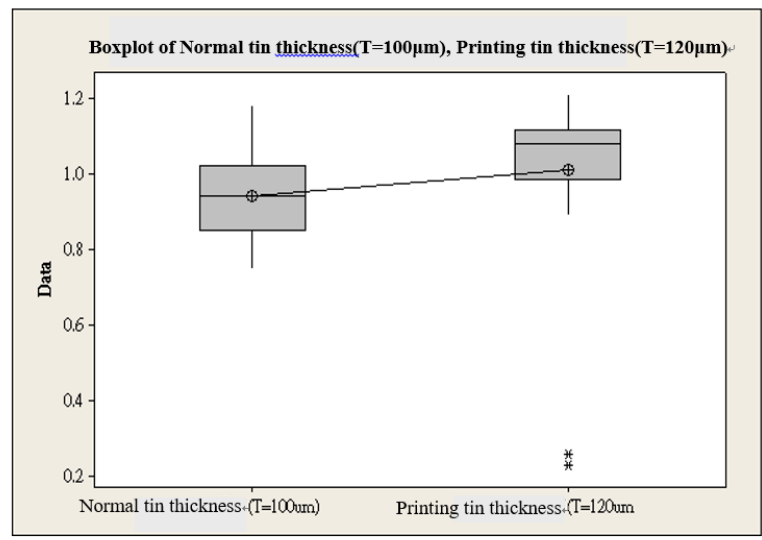

Fig.6. The Boxplot of normal product and tin thickness

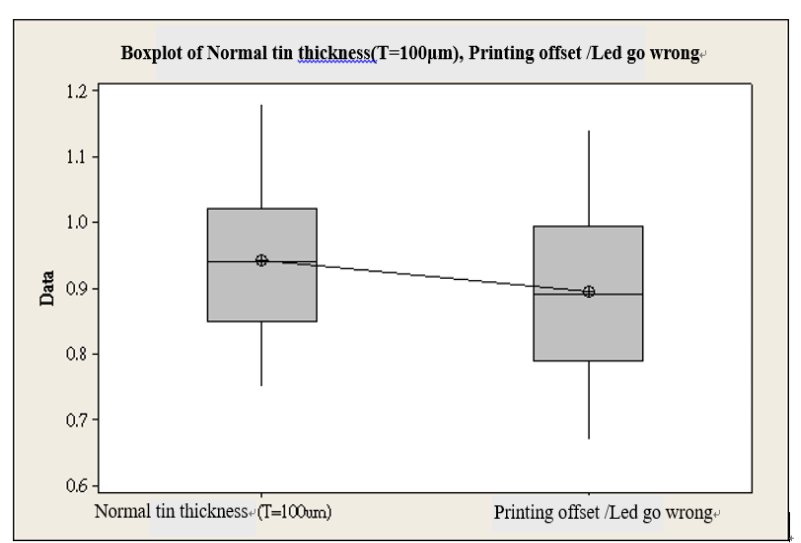

Fig.7. The Boxplot of normal product and offset

In the SMT process, when the LED is placed on the FPC, the solder paste is paste-like and does not have any viscosity. It needs to be heated to $230-250{ }^{\circ} \mathrm{C}$ to melt the solder paste under the soldering part of the part before the LED can be soldered to the FPC. On the PAD. At this time, the heating temperature and time presented by the profile should refer to the reference value provided by the solder paste supplier. Since the reflow zone is the melting point of the solder paste, the welding strength of the part is closely related to the setting of the reflow zone parameter. At present, the lead-free solder paste must have a temperature of $220^{\circ} \mathrm{C}$ to reach 30 to $60 \mathrm{sec}$ and a maximum peak temperature of $240 \pm 10^{\circ} \mathrm{C}$ according to the specification.

\section{$2.4 \quad$ Improve phase}

During the analysis phase, the LED thrust can be increased to $1 \mathrm{~kg}$ by adjusting the solder paste thickness and welding area. Next, to further achieve the target of thrust higher than $1.2 \mathrm{~kg}$, the parameters of SMT must be optimized with experimental design. Besides, because of the exposed area of PAD and customer design, the manufacturing process only needs to be controlled within tolerance.

In the analysis stage, it is known that the reflow zone must reach $220^{\circ} \mathrm{C}$ at $30-60$ seconds, and the peak maximum temperature is $240 \pm 10{ }^{\circ} \mathrm{C}$. At present, the reasonable operating standard of M company is 100um tin thickness, reach $220^{\circ} \mathrm{C}$ at 45 seconds, and the peak temperature is $240^{\circ}$ c. Therefore, this study selected the $2^{3}$ factor experiment and repeated the design for ten times. The experimental conditions were set for the three control factors, solder paste thickness, reflow zone time and peak maximum temperature, as shown in Table 1.

Table 1 Experimental factors and level

\begin{tabular}{|c|c|c|c|}
\hline & $\begin{array}{c}\text { Solder paste } \\
\text { thickness }\end{array}$ & $\begin{array}{c}\text { Reflow } \\
\text { zone time }\end{array}$ & $\begin{array}{c}\text { Peak maximum } \\
\text { temperature }\end{array}$ \\
\hline Level 1 & 100 & 30 & 230 \\
\hline Level 2 & 120 & 60 & 250 \\
\hline
\end{tabular}

Use the Minitab ${ }^{\circledR}$ software to design the experiment and generate a preliminary plan. Then the actual process operation was carried out, and the measured thrust value was input into Minitab ${ }^{\circledR}$ software. Next, an experimental analysis will be performed. Firstly, a factor effect plot was drawn. From Figure 8, the change of the slope is visible. It is preliminarily determined that all three factors were significant. Next, plot the factor interaction diagram to confirm if the factors interact. Figure 9 shows that there is an intersection between the reflow time and the peak temperature, and the initial determination has an interaction.

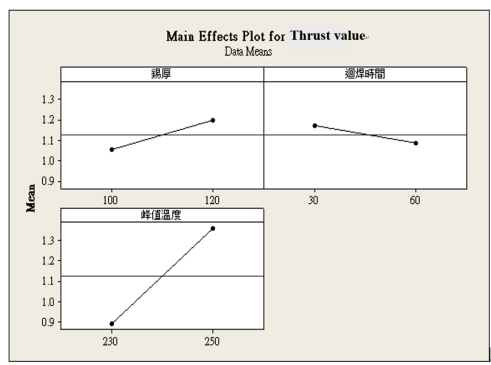

Fig.8. The factor effects plot 


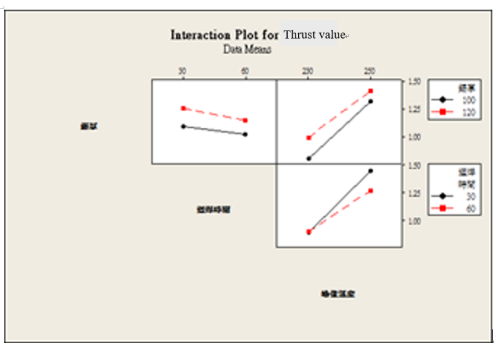

Fig.9. The factor interaction plot

Next, a significant factor is found from the Plato of the factor effect values. As can be seen from Fig. 10, the order of the significant factors is $\mathrm{C}$ (peak temperature), A (tin thickness), $\mathrm{B}$ (reflow time) $\times \mathrm{C}$.

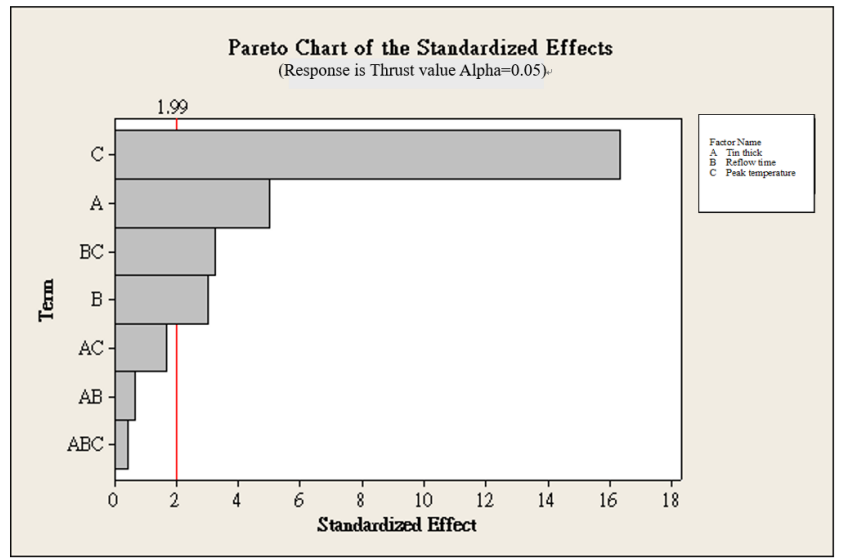

Fig.10. The Pareto plot of the factor effects

Use the Minitab ${ }^{\circledR}$ response value optimization function to find the best combination of process parameters. From Fig. 14 , it is found that the tin thickness is $111 \mathrm{um}$, the reflow time is $40 \mathrm{sec}$, and the peak maximum temperature is 250 degrees, which is the optimum parameter condition of the machine.

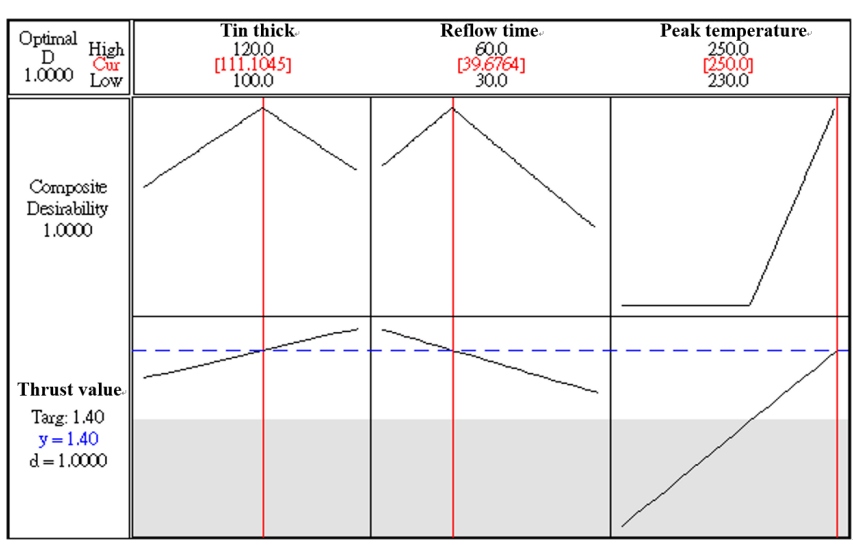

Fig.11. The optimal process parameter combination

Finally, a verification experiment of the optimal process condition combination is performed to confirm whether the obtained parameter condition combination can achieve the target value. The SMT process condition parameters were set to a tin thickness of $111 \mathrm{um}$, a reflow time of $40 \mathrm{sec}$, and a peak maximum temperature of 250 , which was compared with the original. The results of the experiment are shown in Figure 12. It can be seen from the box plot that the improved results are significant.

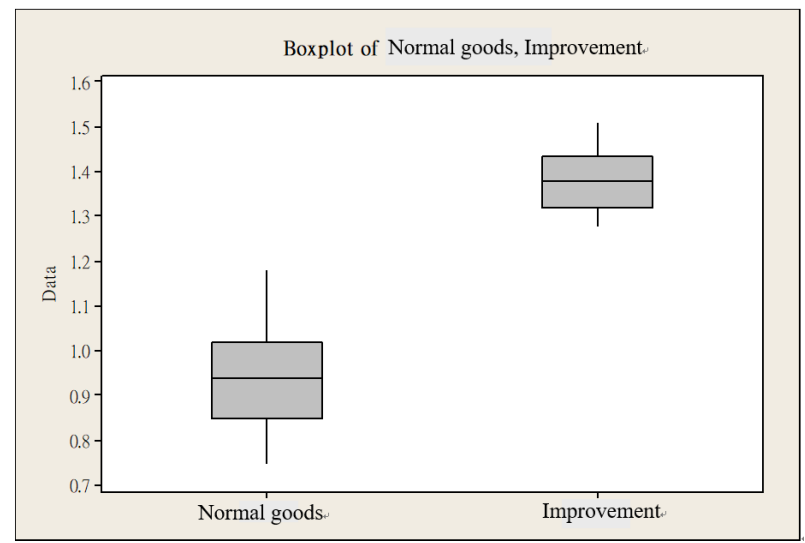

Fig.12. Comparison of the difference between the thrust value of the original product and the improved product

\subsection{Control phase}

The results obtained are then followed by the formulation of relevant standard operating procedures and the establishment of the control table, as shown in Table 2 to avoid the production process defects. Finally, the improved process will be transferred to the actual production line, and the production line will monitor the production process.

Table 2. Process standard operation control table

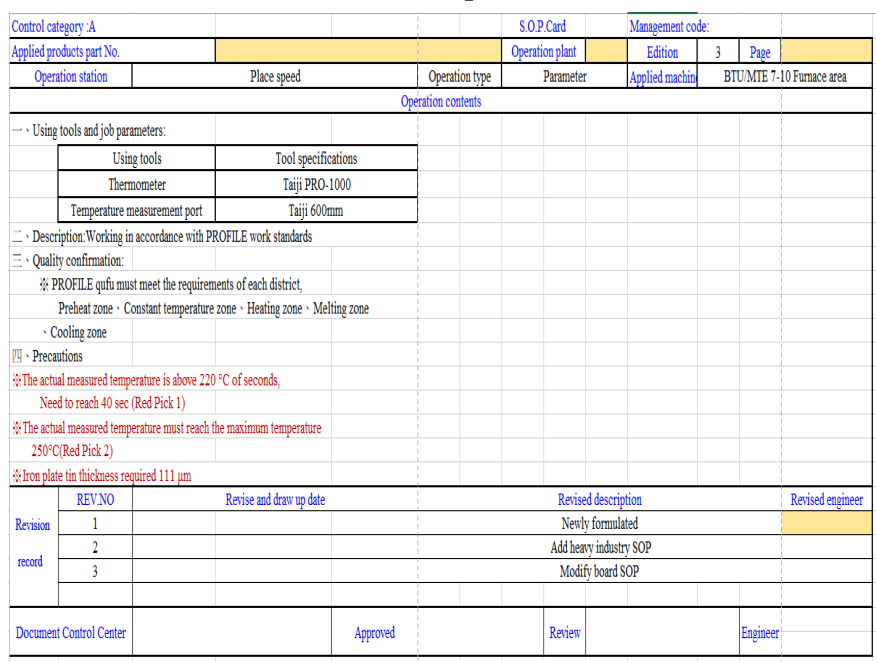

3. Conclusion

This study follows the six-sigma DMAIC method and completes the improvement of SPC parameters of FPC 
manufacturers under the limited resources of the company. Through optimizing process parameters, this study can effectively solve customer complaints. However, electronic components are very fast for new products and replacement. This study only focuses on customer complaints that cause the most significant loss at present. In the future, design for six sigma based on process design will be introduced to prevent the recurrence of problems.

\section{References}

(1) Laureani, A., \& Antony, J. "Leadership-a critical success factor for the effective implementation of Lean Six Sigma", Total Quality Management \& Business Excellence, Vol.29, No.5-6, pp.502-523, 2018.

(2) Shamsuzzaman, M., Alzeraif, M., Alsyouf, I., \& Khoo, M. B. C. "Using Lean Six Sigma to improve mobile order fulfilment process in a telecom service sector", Production Planning \& Control, Vol.29, No.4, pp.301314, 2018.

(3) Lamine, K., \& Lakhal, L. "Impact of TQM/Six Sigma practices on company's performance: Tunisian context", International Journal of Quality \& Reliability Management, Vol.35, No.9, pp.1881-1906, 2018.

(4) Huang, Yuh-Ji, Hsiu-Rong Wei \& Shau-Hwa Yang. "Applying six sigma dmarc methodology to improve the inventory control system", Journal of quality, Vol.24, No.4, pp.280-299, 2017.

(5) Chan, Ku-Chi, Ying Ho, \& Chuen-Sheng Cheng. "Using six sigma methodology to improve the copper plating uniformity in flip chip ball grid array", Journal of quality, Vol.26, No.2, pp.114-125, 2019. 